\title{
Grain Boundary Character Distributions in Ni-16Cr-9Fe Using Selected Area Channeling Patterns: Methodology and Results
}

\author{
DOUGLAS C. CRAWFORD AND GARY S. WAS \\ Department of Nuclear Engineering (D.C.C., G.S.W.) and Department of Materials Science and Engineering (G.S.W.), University of \\ Michigan, Ann Arbor, Michigan 48109
}

\begin{abstract}
KEY WORDS Alloy 600, Grain boundary structure, Misorientation texture
ABSTRACT Selected area channeling patterns imaged on an SEM are digitized and displayed on the screen of a Macintosh computer, on which the user selects channeling bands that are measured to determine orientation. Grain boundary misorientations are found using the orientation information for pairs of grains adjacent at grain boundaries, and the boundaries are classified as low angle boundaries (LABs), coincident site lattice boundaries (CSLBs), or general boundaries (GHABs) based on the misorientation information. The technique was implemented to analyze the grain boundary character distributions (GBCDs) in Ni-16Cr-9Fe. The GBCDs of solution annealed material were similar to those expected in an aggregate of randomly oriented polycrystals. However, sequential thermomechanical treatments $\left(5 \%\right.$ tensile strain $+945^{\circ} \mathrm{C}: 75 \mathrm{~min}+2 \%$ tensile strain $+890^{\circ} \mathrm{C}: 15 \mathrm{~h}+3 \%$ tensile strain $+890^{\circ} \mathrm{C}: 20 \mathrm{~h}$ or $9 \%$ compressive strain $+890^{\circ} \mathrm{C}: 20 \mathrm{~h}+$ $9 \%$ compressive strain $+890^{\circ} \mathrm{C}: 20 \mathrm{~h}+3 \%$ compressive strain $+890^{\circ} \mathrm{C}: 15 \mathrm{~h}$ ) applied after the solution anneal lowered the proportions of GHABs in the GBCDs from 76-79\% to 47-64\%. The CSL-enhanced GBCDs of both the tensile-deformed samples and the compression-deformed sample appear to have evolved mainly through impingement of twin and twin-related boundaries during recrystallization; the CSL-enhanced GBCD of a compression-deformed sample appears to have been influenced by grain rotation processes to a greater degree than were the tensile-deformed samples. The CSL boundaries in the CSL-enhanced GBCDs were, in general, closer to the exact CSL misorientations than were those in the near-random GBCDs of the solution annealed material. An analysis of the distribution of misorientation axes did not indicate any correlation between grain misorientation texture and GBCD evolution.
\end{abstract}

\section{INTRODUCTION}

Recent work that correlates grain boundary misorientation with material properties indicates that a grain boundary's structure affects its susceptibility to some grain boundary phenomena such as grain boundary diffusion, segregation, sliding, and intergranular fracture (Pumphrey, 1976; Watanabe, 1985). The present paper describes a method used to obtain and analyze grain boundary character distributions (GBCDs) in high purity $\mathrm{Ni}-16 \mathrm{Cr}-9 \mathrm{Fe}$ (which is similar to Alloy 600) altered through deformation and heat treatment steps. Alloy 600 has been shown to exhibit a variety of grain boundary phenomena (e.g., chromium depletion, precipitation, and intergranular creep) of which some have been linked to intergranular stress corrosion cracking (IGSCC) performance (Was, 1989). If the proportions of special boundaries in Alloy 600 can be increased, then perhaps the IGSCC behavior of this alloy can be improved.

\section{BACKGROUND \\ Grain Boundary Properties}

This section reviews recent work that correlates grain boundary misorientation with material properties, and demonstrates that the proportions of special boundaries in a material can be increased. The published work indicates that, in general, low angle boundaries and boundaries near CSL orientations are more resistant to grain boundary phenomena, particularly those related to mechanical properties. Priester (1989) also arrives at this conclusion, but further concludes that other phenomena (e.g., intergranular diffusion and segregation) depend more on grain boundary structure determined by boundary plane orientation than on boundary misorientation. The CSL model characterizes a grain boundary as a low angle boundary (LAB), a coincident site lattice boundary (CSLB), or a general high angle boundary (GHAB) depending on the relative misorientation between the two crystals adjacent at the boundary (Pumphrey, 1976). A coincident site lattice (CSL) is the superlattice of common points formed when two crystal lattices are oriented such that they have coincident lattice points. CSLs are characterized by the parameter $\Sigma$, which is the reciprocal den-

Received July 23, 1990; accepted in revised form January 7, 1991.

Address reprint requests to Doug Crawford, Fuels and Processes Division, Argonne National Laboratory-West, P.O. Box 2528, Idaho Falls, ID 83403-2528. 
TABLE 1. Calculated and simulated random GBCDs

\begin{tabular}{|c|c|c|c|c|c|}
\hline \multirow[b]{2}{*}{ Authors } & \multirow[b]{2}{*}{$\mathrm{LABs}^{1}(\%)$} & \multicolumn{3}{|c|}{$\mathrm{CSLBs}^{2}(\%)$} & \multirow[b]{2}{*}{$\mathrm{GHABs}^{3}(\%)$} \\
\hline & & $\bar{\Sigma} \leq 25$ & $\Sigma \leq 37$ & $\bar{\Sigma} \leq 49$ & \\
\hline Garbacz and Grabski (1989) & 2.21 & 8.61 & 10.81 & 12.92 & $84.9-89.2$ \\
\hline Warrington and Boon (1975) & 1.98 & 9.0 & — & - & 89.0 \\
\hline Randle and Ralph (1988a) & 2.8 & 9.7 & 12.5 & - & $84.7-87.5$ \\
\hline
\end{tabular}

${ }^{1} \mathrm{LABs}$ : low angle boundaries.

${ }^{2}$ CSLBs: coincident site lattice boundaries.

${ }^{3} \mathrm{GHABs}$ : general high angle boundaries; values depend on the limiting value of $\Sigma$.

sity of coincident sites; that is, the reciprocal of the number of coincident sites per unit volume divided by the number of crystal lattice points per unit volume. Thus, a CSLB is a grain boundary at which the grains lie sufficiently close to a CSL misorientation relationship.

In fatigue tests of coarse-grained $\mathrm{Ni}$ at $300^{\circ} \mathrm{C}, \mathrm{Lim}$ and Raj (1984) found that non-CSLBs and high $\Sigma$ CSLBs were the first to form slip-induced cavities in fatigue tests. Lower $\Sigma$ CSLBs had greater resistance to cavitation, while coherent twin boundaries had the greatest resistance. Similar results were found in fatigue tests of pure polycrystalline copper (ButronGuillen et al., 1990) and in creep tests of type 304 stainless steel (Don and Majumdar, 1986) and alpha iron with 0.8 at\% tin (Watanabe, 1983). $\Sigma 9$ boundaries (Watanabe et al., 1981) in <10T0>-tilt zinc biocrystals and $\Sigma 3$ and $\Sigma 13$ boundaries in aluminum bicrystals (Kokawa et al., 1979) were more resistant to grain boundary sliding than were high angle boundaries. In other work, Watanabe et al. (1982) found that stepwise loading of beta brass tensile specimens wetted with liquid gallium at $30^{\circ} \mathrm{C}$ produced cracks that initiated at, and propagated intergranularly along, GHABs rather than along LABs or CSLBs. In fact, cracks propagating along general boundaries that encountered CSLBs temporarily changed to a transgranular cracking mode until encountering other GHABs. Chou et al. (1983) found that microhardness values near LABs and CSLBs in niobium bicrystals were less than those near GHABs.

Grain boundary phenomena that appear to involve effects that are more chemical, rather than mechanical, in nature do not correlate as well with grain boundary type as determined by the CSL model. In general, LABs and coherent twin boundaries might show special behavior in these cases, but CSLBs do not necessarily behave differently than GHABs. Intergranular processes such as sensitization (Cr depletion) (Bennett and Pickering, 1987; Ortner and Randle, 1989), hydrogen-induced cracking and precipitation (Sato et al., 1986), and phosphorous segregation (Ogura et al., 1987) appear to depend not only on the relative misorientation at the grain boundary, but also on the grain boundary plane.

\section{Grain Boundary Character Distributions}

In light of studies relating grain boundary properties to grain boundary misorientation (from which structure can be inferred; e.g., Pumphrey, 1976), Watanabe $(1984,1986)$ proposed the concept of grain boundary design; that is, a material with a relatively large proportion of special grain boundaries might be expected to be more resistant to grain boundary phenomena that lead to failure. Previous work has demonstrated that proportions of CSLBs and LABs in a material can be enhanced through thermomechanical treatment. In this work, the grain boundary character distribution (GBCD) is taken to be the relative proportions of CSLBs, LABs, and GHABs.

Using the CSL model, Randle and Ralph (1988a) calculated the probabilities of finding given misorientations (corresponding to boundary types) between two randomly oriented crystals, while Warrington and Boon (1975) calculated the geometrical probabilities of obtaining CSL misorientations from random crystal rotations across a grain boundary. Garbacz and Grabski (1989) generated misorientation probabilities from a model of polycrystalline aggregate in which each of the crystals (grains) were randomly oriented. Table 1 lists the GBCD values expected in a random distribution of grain boundaries or rotational misorientations as determined from each of the aforementioned papers. For our purposes, the proportions of boundary types in all three random GBCDs are essentially the same: that is, 2-3\% LABs, 84-90\% GHABs, and 9-13\% CSLBs depending on the $\Sigma$ limit for CSL classification. Because Garbacz and Grabski's work takes some account of the effect of a spatial aggregate of adjoining grains on misorientation distribution, their values are used for comparison with the present experimental results.

Watanabe et al. (1989) determined the GBCDs for Fe-6.5 wt\% Si ribbons given different post-solidification annealing treatments. The ribbon given the longer time, higher temperature anneal $\left(1,090^{\circ} \mathrm{C}\right.$ for 1 hour $)$ contained 54.8\% GHABs, while the ribbons given lower temperature and/or shorter time anneals contained 86-87\% GHABs and considerably smaller proportions of CSLBs and LABs. Lower temperature, longer time anneals resulted in slightly smaller proportions of GHABs in recrystallized $\mathrm{Fe}-3$ wt\% Si (Watanabe et al., 1986).

Randle and Brown (1988) demonstrated that the GBCD in an austenitic stainless steel tubing can be altered by thermomechanical treatments. Table 2 shows the GBCDs resulting from tensile strains and subsequent heat treatments given to annealed stainless steel tubing samples with $19 \mu \mathrm{m}$ grains. The thermomechanical treatments were able to reduce the proportion of GHABs from $67 \%$ in the control sample, to as low as $48 \%$ in the $7 \%$ tensile-strained plus $950^{\circ} \mathrm{C}: 9 \mathrm{~m}$ sample. They attributed the increase in CSLB propor- 
TABLE 2. GBCDs in austenitic stainless steel tubing after $930^{\circ} \mathrm{C}: 1 \mathrm{~h}$ anneal (data from Randle and Brown, 1988)

\begin{tabular}{lccc}
\hline Steps & $\begin{array}{c}\text { LABs }^{1} \\
(\%)\end{array}$ & $\begin{array}{c}\mathrm{CSLBs}^{2} \\
(\%)\end{array}$ & $\begin{array}{c}\mathrm{GHABs}^{3} \\
(\%)\end{array}$ \\
\hline Control & 9 & 35 & 67 \\
$2 \%$ tensile strain $+950^{\circ} \mathrm{C}: 90 \mathrm{~min}$. & 8 & 29 & 63 \\
$2 \%$ tensile strain $+950^{\circ} \mathrm{C}: 180 \mathrm{~min}$. & 8 & 37 & 55 \\
$7 \%$ tensile strain $+950^{\circ} \mathrm{C}: 9 \mathrm{~min}$. & 21 & 30 & 48 \\
$7 \%$ tensile strain $+950^{\circ} \mathrm{C}: 14 \mathrm{~min}$. & 7 & 37 & 56 \\
\hline
\end{tabular}

${ }^{1} \mathrm{LABs}$ : low angle boundaries.

${ }^{2}$ CSLBs coincident site lattice boundaries with $\Sigma \leq 37$.

${ }^{3}$ GHABs: general high angle boundaries.

tions to grain rotations that occur at elevated temperatures during the incubation period before the onset of anomalous grain growth (secondary recrystallization). In their interpretation (Randle and Brown, 1987, 1989), an uneven distribution of residual strain will provide a driving force for grain boundary migration, but when the migration activation energy (including pinning and drag effects) is too high, grain boundary recovery relieves the strain energy. During recovery, lattice dislocations impinge upon grain boundaries; these dislocations are referred to as extrinsic grain boundary dislocations (EGBDs). As the boundaries attempt to lower their energy they will absorb the EGBDs, causing the grains to rotate by a diffusion-controlled grain boundary sliding process. As the grain boundaries approach the lower energy CSL orientations, the driving force for rotation is reduced; thus, CSLB orientations become more prevalent.

\section{GRAIN BOUNDARY CHARACTERIZATION METHODOLOGY}

This section describes the methodology we used for determining GBCDs in Ni-16Cr-9Fe. In the past, characterization of large numbers of grain boundaries had been difficult due to resolution limits on X-ray systems or sample size limitations for TEM. Implementation of selected area channeling pattern (SACP) or electron backscattering pattern (EBSP) techniques allows collection of orientation data from many grains in a macroscopic sample. However, subsequent analysis of a large number of SACPs or EBSPs can be cumbersome. Computerized methods of indexing or analyzing SACPs (Farrow and Joy, 1981; Ishida et al., 1981; Newbury and Joy, 1971; Vale, 1985) and EBSPs (Dingley et al., 1987) have been reported and, if properly implemented, can reduce the time and effort necessary to obtain orientation information from the patterns. The computerized method used in the present work to obtain grain orientations implements schemes developed by Heilmann et al. (1982).

On an SEM equipped for SACP operation mode, SACPs can be imaged on the instrument's CRT at standard imaging scan speeds. These patterns can be recorded on film within the times typically used to record standard SEM images from a photo quality CRT (40$50 \mathrm{~s})$. Recording onto Polaroid film the SACPs from a large number of grains in a sample can be expensive, however; so for the present work, a scheme for collect- ing and indexing digitized SACPs was successfully implemented.

\section{SACP Imaging Technique}

SACPs were imaged from flat surfaces on electropolished samples using a Hitachi S-520 scanning electron microscope. Proper adjustment of the associated Hitachi S-6579 electron channeling unit configured the electron column for SACP imaging in a manner similar to that reported by Joy et al. (1982). The backscattered electron intensity was detected with a GW Electronics concentric backscattered electron detector and imaged on the instrument's CRT. A Kevex $8000 \mathrm{X}$-ray analysis system equipped with Kevex advanced imaging software was used to digitize the SACP images. The digitized images span 512 horizontal pixels by 256 vertical pixels and are stored in 8-bit bytes with 64 gray levels, requiring approximately 132 kilobytes of disk storage per image. Because the images were subsequently displayed on a Macintosh computer screen, the Kevex system's x-scan had to be recalibrated to record intensities based on a 1:1 pixel shape. Although the images appeared distorted on the Kevex screen, they appeared in proper proportion on the Macintosh screen. Using File Transfer Protocol (FTP) software on the Kevex system and on a Sun $3 / 60$ workstation, the digitized images were transferred to the Sun 3/60 over a computer network. The directory on the Sun computer was configured to act as a Macintosh file-server on a Macintosh Appletalk network, so the images could be accessed by Macintosh software.

\section{SACP Indexing}

A Macintosh computer program, ECPMeasure, written for this work using a Pascal compiler, allows the user to display Kevex image files on the screen of a Macintosh computer (provided the computer is configured with an 8-bit video board and a grayscale or color monitor). To index the pattern, the user selects three channeling bands that form a triangle around the pattern center, and ECPMeasure prompts the user to input two points from each side of each band. (If the SACP is close to a major pole-e.g., [100] or [110]three known bands that intersect at the pole are chosen.) ECPMeasure then calculates the angles between bands, the band widths, and the band width ratios and stores the information to a user-named file for later use. The program allows the user to continue displaying and measuring from other images, storing data in the same file or in different files if desired.

Heilmann's program ORIENT (Heilmann et al., 1982 ) is used to index each SACP and find the orientation of the associated grains. ORIENT is written in FORTRAN and, for this work, was modified to run on a Macintosh computer. The program was also modified to accept batch files of data from ECPMeasure and output batch files of data to user-named files. ORIENT indexes the selected planes from each pattern, determines each pattern's beam direction, and calculates a rotation matrix [R] representing the orientation of each corresponding grain with respect to some reference coordinate frame (Young et al., 1973). Another modification to ORIENT allows the program to index 
patterns that are oriented near low index poles (e.g., [100] or [110]) and on which the user cannot find three channeling bands that form a triangle around the pattern center. This part of the program requires interactive input from the user in selecting consistent permutations of channeling band indices based on the location of the pattern with respect to the stereographic unit triangles located between [100], [110], and [101].

Another program, ECPOrient, with the combined measuring and orientation capability of the ECPMeasure and the ORIENT programs has recently been completed. The program runs on a properly equipped Macintosh computer and implements the standard Macintosh user interface. Although ECPOrient was used for only a small part of the present work, it is mentioned here because the program allows on-line orientation determination of SACPs using a Macintosh computer; proper interfacing between the computer and the SEM would allow the SACPs to be digitized and displayed directly on the Macintosh computer.

To characterize grain boundaries, the user selects pairs of grains adjacent at grain boundaries seen in a backscattered electron image of the sample surface, in which the microstructure is indicated by electron channeling contrast (Davidson, 1984; Joy et al., 1982); individual grains are given numbers. Such an image is shown in Figure 7a. A file of grain pair numbers is then fed into Heilmann's program MISMAT (Heilmann et al., 1982), which can access a file of grain rotation matrices output by ORIENT and calculate the misorientation between the grains for each grain pair. MISMAT is written in FORTRAN and has been modified to run on a Macintosh computer and to accept and to output batch files of data. MISMAT calculates a crystallographic axis and angle of misorientation and a misorientation matrix $[\mathrm{M}]$ for each boundary represented by a grain pair. For example, for adjacent grains $a$ and $b$ :

$$
[\mathrm{M}]=\left[\mathrm{R}_{\mathrm{a}}\right]^{-1}\left[\mathrm{R}_{\mathrm{b}}\right] \text {. }
$$

Data output from MISMAT are fed into another Macintosh program called FindCSL, which was written in FORTRAN for this work. FindCSL will classify each boundary misorientation in terms of the CSL model. A coincident boundary (CSLB) characterized by $\Sigma$ is a boundary that meets Brandon's criterion (Brandon, 1966):

$$
\Delta \theta \leq \Delta \Theta_{\mathrm{b}}=15^{\circ} / \Sigma^{1 / 2}
$$

where $\Delta \theta$ is determined from the deviation matrix [D] that represents the deviation of the boundary misorientation matrix $[\mathrm{M}]$ from an exact CSL misorientation matrix $\left[\mathbf{M}_{\mathrm{cs} 1}\right]$.

$$
\begin{gathered}
{[D]=\left[M_{\mathrm{cs} 1}\right]^{-1}[M] .} \\
\left.\Delta \Theta=\arccos \left\{\left(D_{11}+D_{22}+D_{33}\right)-1\right] / 2\right\} .
\end{gathered}
$$

Low angle boundaries (LABs) are any boundaries with a misorientation angle of less than 15 degrees. All nonCSL and non-LA boundaries are classified here as gen- eral high angle boundaries (GHABs). FindCSL lists the classification of each boundary and the proportion of boundary types for all the boundaries in the input batch (generally all the boundaries characterized from a single sample). The program allows the user to specify, in the MISMAT input file of grain pairs, which boundaries are apparent coherent twin boundaries; FindCSL will then note which of these boundaries are in fact $\Sigma 3$ boundaries and then leave them out of the GBCD analysis.

The limiting value of $\Sigma$ for this work was chosen to be 49 based on the work of Shvindlerman and Straumal (1985). They gathered reported data on the existence of special properties and special structure at CSLBs as a function of $\Sigma$ number and temperature. Their work suggests that above some value of $\Sigma$, CSLBs are no longer special, and that this transition value of $\Sigma$ decreases with increasing temperature. From their work, one might predict that the transition value of $\Sigma$ for a homologous temperature of approximately $0.4 \mathrm{~T}_{\mathrm{m}}$ is near 49 (recent IGSCC experiments in our laboratory have been conducted on the heats used for this work at $\mathrm{T} / \mathrm{T}_{\mathrm{m}}=0.38$ ).

The Macintosh program TexturePlot was written in Pascal for this work and allows the user to display a sample's distribution of beam directions (from an ORIENT output file) or misorientation axes (from a MISMAT output file) in the stereographic unit triangle. Textures or preferred orientations normal to the beam direction and grain misorientation textures can then be represented graphically.

\section{EXPERIMENTAL PROCEDURE}

The Materials Preparation Center of Ames Laboratory prepared the three heats of $\mathrm{Ni}-16 \mathrm{Cr}-9 \mathrm{Fe}$ (designated $A, B$, and C) used for this study. Combustion chromatographic analysis indicated that these heats contained less than 25 wppm carbon. The material arrived in the form of 3-mm diameter swaged rods. Round tensile samples with flat surfaces were machined according to the drawing in Figure 1. All machined samples were annealed at $1,200^{\circ} \mathrm{C}$ for $1 \mathrm{~h}$ under flowing argon followed by a water quench. This first anneal resulted in a grain size of approximately $235 \mu \mathrm{m}$. Samples were then given a sequence of thermomechanical treatments as shown in Table 3. Following the final heat treatment, the samples were mechanically polished with 600 grit and Struers 2400 grinding paper and 1 or $3 \mu \mathrm{m}$ diamond paste. The samples were then electropolished in a solution of $20 \mathrm{vol}$.\% concentrated perchloric acid in ethanol at approximately $-40^{\circ} \mathrm{C}$ and etched in $20 \mathrm{vol} \%$ concentrated nitric acid in methanol. The grain boundary character distribution (GBCD) for each sample was found using the technique described earlier. Samples A2 and B1 were polished and characterized after each of the treatments indicated in Table 3, whereas all other samples were polished and characterized only after their final treatment.

Samples were strained in tension at an extension rate of approximately $10^{-4} \mathrm{inch} / \mathrm{sec}$ using a constant extension rate testing machine. Tensile strain values are all based on each sample's initial flat surface length of 5/16 inch. To examine the effect of compres- 

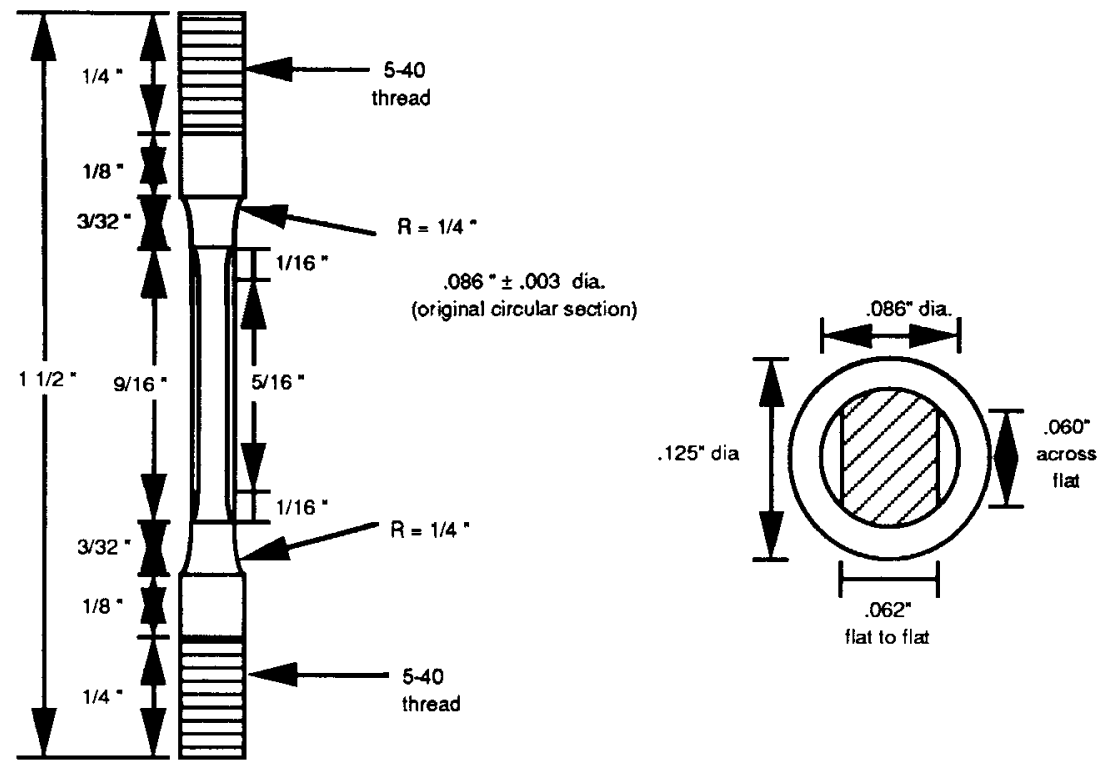

Fig. 1. Sketch of round tensile bar with parallel flat surfaces.

sive prestrain on GBCD evolution, a round-section tensile sample (sample B1) was compressed between two 9/16 inch square WC blocks on an Instron testing machine transverse to the gauge length. Initially flat surfaces were put onto the round-section gauge length by compressing the as-machined sample to 0.066 inch thickness (or $24 \%$ of the initial diameter) as indicated in Figure 2. Subsequent heat treatment and deformation treatments were then carried out as indicated in Table 3. The indicated compressive strain values are all percentages of the sample's original 0.066 inch thickness.

\section{RESULTS AND DISCUSSION}

This section discusses the resulting GBCDs in terms of 1) the relative proportions of boundary types, 2) evidence of recrystallization and polygonization, 3) distributions of CSLBs by $\Sigma$ and their relative deviation from exact coincidence, and 4) the grain misorientation

TABLE 3. Schedule of thermomechanical treatments

\begin{tabular}{|c|c|c|c|c|}
\hline Heat & Sample ${ }^{1}$ & Processing & Recrystallized & Grain Size \\
\hline \multirow[t]{3}{*}{$\overline{\mathrm{A}}$} & 1 & $1,200^{\circ} \mathrm{C}: 1 \mathrm{hr}(\mathrm{SA})$ & yes & $235 \mu \mathrm{m}$ \\
\hline & $2 a$ & $1,200^{\circ} \mathrm{C}: 1 \mathrm{hr}(\mathrm{SA})$ & yes & $231 \mu \mathrm{m}$ \\
\hline & $\begin{array}{l}2 b \\
2 c^{2} \\
2 d \\
2 e \\
2 f\end{array}$ & $\begin{aligned} \mathrm{SA} & +5 \% \text { tension }+945^{\circ} \mathrm{C}: 75 \mathrm{~min} \\
& +2 \% \text { tension }+890^{\circ} \mathrm{C:10} \mathrm{h} \\
& +890^{\circ} \mathrm{C}: 5 \mathrm{~h} \\
& +3 \% \text { tension }+890^{\circ} \mathrm{C}: 20 \mathrm{~h} \\
& +3 \% \text { tension }+890^{\circ} \mathrm{C:15} \mathrm{h}\end{aligned}$ & $\begin{array}{l}\text { no } \\
\text { no } \\
\text { no } \\
\text { yes } \\
\text { no }\end{array}$ & $321 \mu \mathrm{m}$ \\
\hline \multirow[t]{4}{*}{ B } & $\begin{array}{l}1 \mathrm{a} \\
1 \mathrm{~b} \\
1 \mathrm{c} \\
1 \mathrm{~d}\end{array}$ & $\begin{aligned} \mathrm{SA} & +9 \% \text { compression }+890^{\circ} \mathrm{C}: 20 \mathrm{~h} \\
& +9 \% \text { compression }+890^{\circ} \mathrm{C}: 20 \mathrm{~h} \\
& +3 \% \text { compression }+890^{\circ} \mathrm{C}: 15 \mathrm{~h} \\
& +3 \% \text { compression }+890^{\circ} \mathrm{C}: 20 \mathrm{~h}\end{aligned}$ & $\begin{array}{l}\text { yes } \\
\text { yes } \\
\text { little } \\
\text { yes }\end{array}$ & $236 \mu \mathrm{m}$ \\
\hline & 2 & $\begin{aligned} \mathrm{SA} & +3 \% \text { tension }+890^{\circ} \mathrm{C}: 15 \mathrm{~h} \\
& +3 \% \text { tension }+890^{\circ} \mathrm{C}: 15 \mathrm{~h} \\
& +3 \% \text { tension }+890^{\circ} \mathrm{C}: 20 \mathrm{~h}\end{aligned}$ & no & \\
\hline & 3 & $\begin{aligned} \mathrm{SA} & +5 \% \text { tension }+945^{\circ} \mathrm{C}: 75 \mathrm{~min} \\
& +2 \% \text { tension }+890^{\circ} \mathrm{C}: 15 \mathrm{~h} \\
& +3 \% \text { tension }+890^{\circ} \mathrm{C}: 20 \mathrm{~h}\end{aligned}$ & mostly & $446 \mu \mathrm{m}$ \\
\hline & 4 & $1,200^{\circ} \mathrm{C}: 1 \mathrm{~h}(\mathrm{SA})$ & yes & \\
\hline \multirow[t]{2}{*}{$\mathrm{C}$} & 1 & $1,200^{\circ} \mathrm{C}: 1 \mathrm{~h}(\mathrm{SA})$ & yes & \\
\hline & 2 & $\begin{aligned} \mathrm{SA} & +5 \% \text { tension }+890^{\circ} \mathrm{C}: 15 \mathrm{~min} \\
& +3 \% \text { tension }+890^{\circ} \mathrm{C}: 20 \mathrm{~h}\end{aligned}$ & yes & \\
\hline
\end{tabular}

ISample designation $\mathrm{A} 1 \mathrm{a} ; \mathrm{A}$ = heat, 1 = sample no., a = processing step.

${ }^{2}$ SACPs from sample A2c were extremely distorted and could not be indexed. 


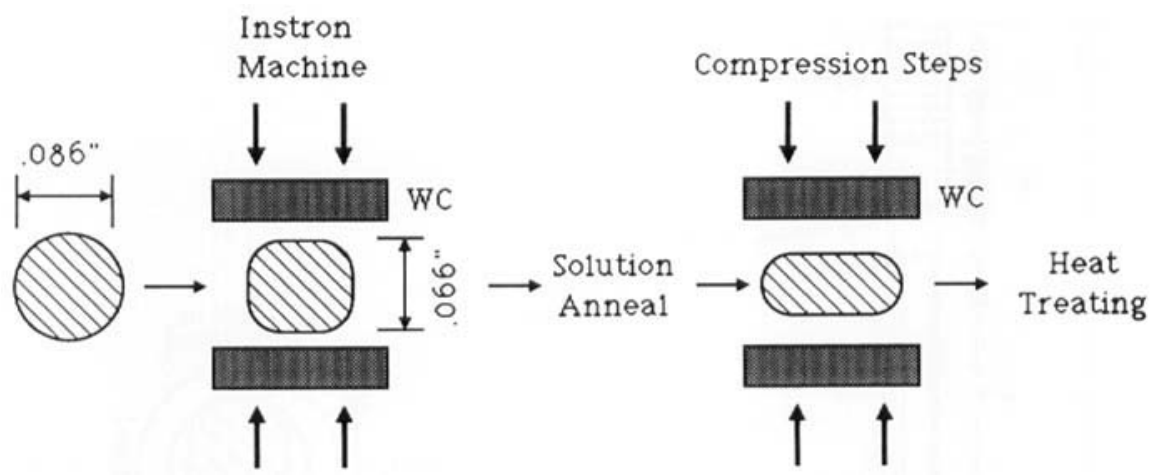

Fig. 2. Schematic of sample B1 cross-section going through compression sequence.

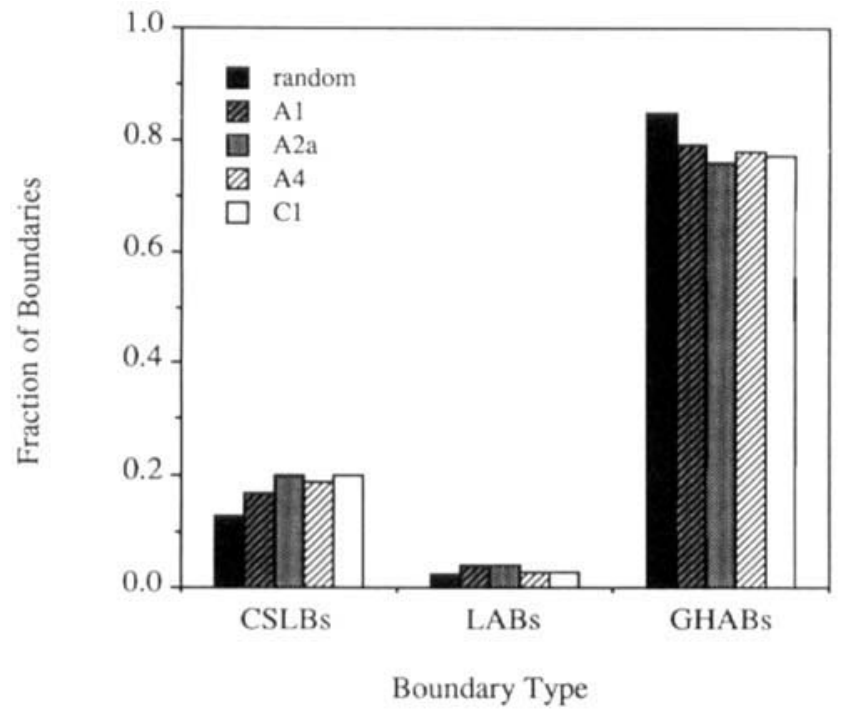

Fig. 3. Comparison of GBCDs for G\&G's random distribution (Garbacz and Grabski, 1989) and samples annealed at 1,200' ${ }^{\circ}: 1 \mathrm{~h}$.

texture as represented by distributions of misorientation axes in the unit triangle.

\section{Relative Proportions of Boundary Types}

Comparison of the GBCDs for the annealed samples $\mathrm{A} 1, \mathrm{~A} 2 \mathrm{a}, \mathrm{B} 4$, and $\mathrm{C} 1$ with that of Garbacz and Grabski's random simulation (Figure 3) shows that the annealed samples have a nearly random distribution of grain boundaries. Also, the fact that the GBCDs for the annealed samples are very similar demonstrates that the characterization process is reproducible.

Figure 4 shows the GBCD evolution through the processing sequence given to sample A2. The figure shows that the first two treatments decreased the GHAB proportion somewhat, but only the third step reduced it significantly. As the GHAB proportion decreased, the CSLB proportion increased. However, repeating the

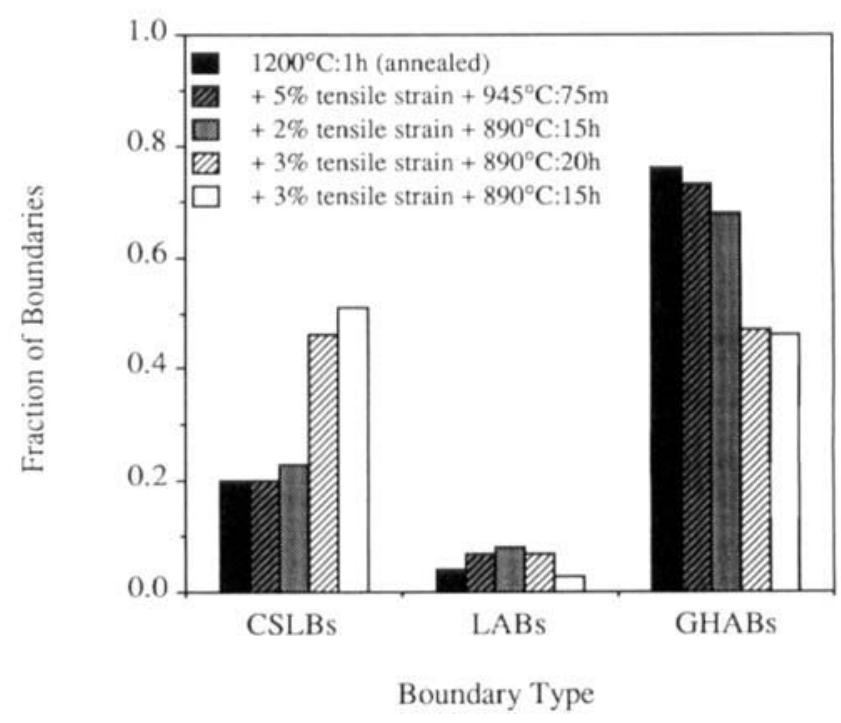

Fig. 4. GBCD evolution for sample A2.

third step (3\% tensile strain followed by $890^{\circ} \mathrm{C}$ heat treatment) did not significantly enhance the effect.

Because the third processing step on sample A2 was so effective in altering the sample's GBCD, the same step was repeated three times on sample B2, after which the sample was characterized. However, Table 4 shows that repeating the $3 \%$ tensile strain $+890^{\circ} \mathrm{C}$ heat treatment did not significantly change the GBCD from that of an annealed sample. To ensure that the enhanced GBCD after the third processing step on sample A2 was reproducible, sample B3 was characterized after receiving the same processing sequence. Figure 5 compares the GBCD for sample B3 with that from the third processing step on sample A2. Although the two distributions are not statistically the same, we see that the processing sequence does in fact decrease the proportion of GHABs and increase the proportion of CSLBs in the GBCDs. 


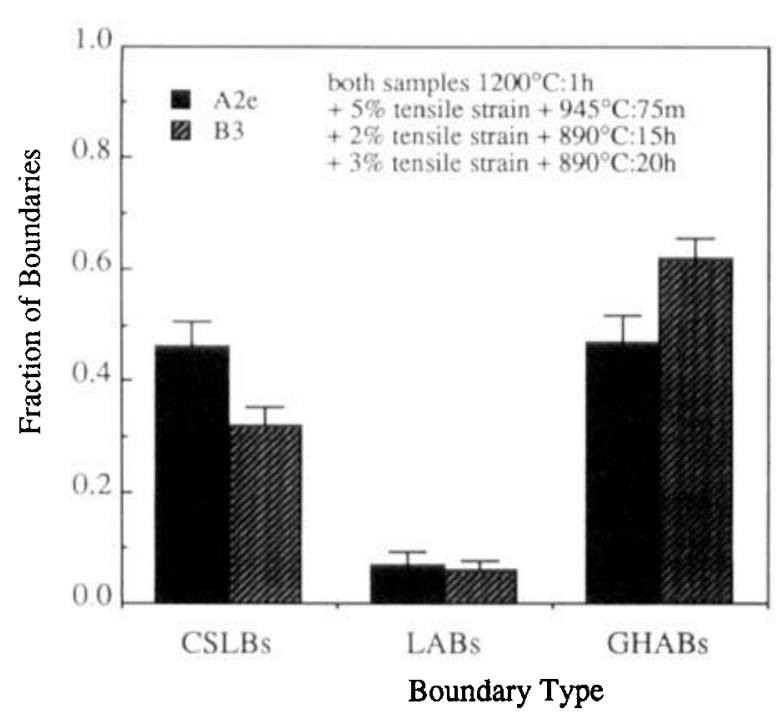

Fig. 5. GBCDs for samples A2e and B3 which received similar thermomechanical treatments.

Figure 6 shows the progression of GBCDs through the sequence of thermomechanical steps performed on sample B1. The initial steps involving $9 \%$ compression did not do much to alter the GBCD from the annealed condition (note that the annealed sample data in Figure 6 are those from sample B4). However, the third (3\%) compression step significantly altered the GBCD. Repeating this step apparently eliminated the enhancement seen.

To assess the statistical accuracy of our experimentally determined GBCDs, we have used counting statistics to find error bounds for GBCD values. The

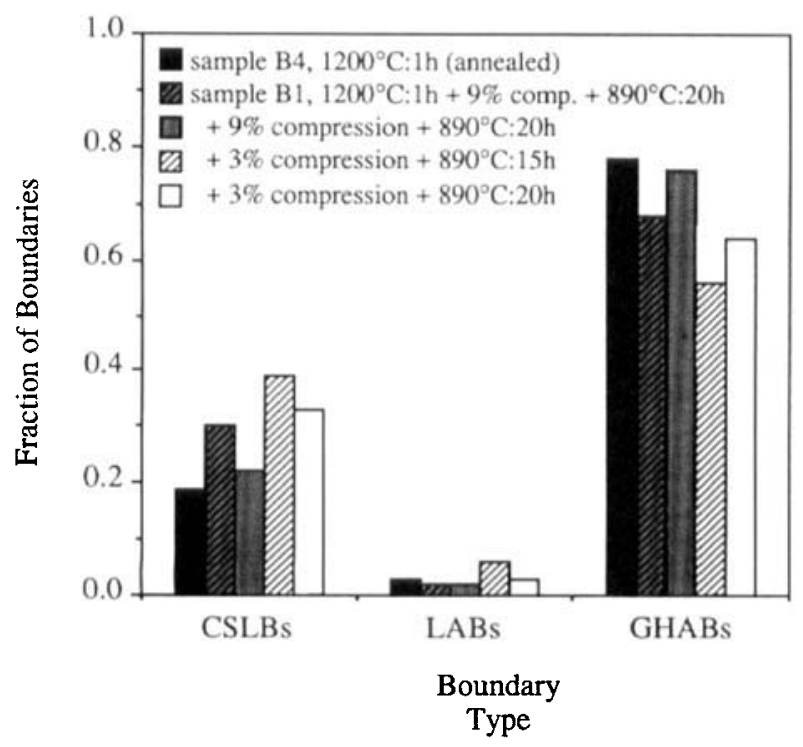

Fig. 6. GBCD evolution for sample B1 compared to the GBCD for annealed sample B4.
TABLE 4. GBCDs from characterized samples

\begin{tabular}{lrcccc}
\hline Sample & Total $^{\mathbf{1}}$ & $\begin{array}{c}\text { CSLB }^{2} \\
(\%)\end{array}$ & $\begin{array}{c}\text { LAB } \\
(\%)\end{array}$ & $\begin{array}{c}\text { GHAB } \\
(\%)\end{array}$ & $\begin{array}{c}\text { TR }^{\mathbf{3}} \\
(\%)\end{array}$ \\
\hline A1 & $\mathbf{1 3 9}$ & $\mathbf{1 7} \pm \mathbf{3 . 2}$ & $\mathbf{4} \pm \mathbf{1 . 7}$ & $79 \pm \mathbf{3 . 5}$ & $\mathbf{3 8}$ \\
A2a & 151 & $20 \pm 3.3$ & $\mathbf{4} \pm 1.6$ & $76 \pm 3.5$ & $\mathbf{4 7}$ \\
A2b & 122 & $20 \pm 3.6$ & $7 \pm 2.3$ & $73 \pm 4.0$ & 56 \\
A2d & 73 & $23 \pm 4.9$ & $8 \pm 3.2$ & $68 \pm \mathbf{5 . 5}$ & 59 \\
A2e & 115 & $46 \pm \mathbf{4 . 6}$ & $7 \pm 2.4$ & $47 \pm 4.7$ & 89 \\
A2f & $\mathbf{8 0}$ & $\mathbf{5 1} \pm \mathbf{5 . 6}$ & $3 \pm 1.9$ & $46 \pm \mathbf{5 . 6}$ & 83 \\
B1a & $\mathbf{1 0 3}$ & $30 \pm 4.5$ & $2 \pm 1.4$ & $68 \pm 4.6$ & 71 \\
B1b & $\mathbf{5 8}$ & $22 \pm 5.4$ & $2 \pm 1.8$ & $76 \pm \mathbf{5 . 6}$ & 54 \\
B1c & $\mathbf{1 0 9}$ & $39 \pm 4.7$ & $6 \pm 2.3$ & $\mathbf{5 6} \pm 4.8$ & 67 \\
B1d & $\mathbf{9 2}$ & $33 \pm \mathbf{4 . 9}$ & $3 \pm 1.8$ & $64 \pm \mathbf{5 . 0}$ & 78 \\
B2 & $\mathbf{8 9}$ & $\mathbf{2 6} \pm \mathbf{4 . 7}$ & $2 \pm 1.5$ & $72 \pm 4.8$ & $\mathbf{4 8}$ \\
B3 & $\mathbf{2 0 7}$ & $32 \pm 3.2$ & $6 \pm 1.7$ & $62 \pm \mathbf{3 . 4}$ & 70 \\
B4 & $\mathbf{1 5 2}$ & $\mathbf{1 9} \pm 3.2$ & $\mathbf{3} \pm 1.4$ & $78 \pm \mathbf{3 . 4}$ & 28 \\
C1 & $\mathbf{2 2 9}$ & $20 \pm 2.6$ & $\mathbf{3} \pm 1.1$ & $\mathbf{7 8} \pm \mathbf{3 . 4}$ & 31 \\
C2 & $\mathbf{1 7 8}$ & $\mathbf{3 0} \pm \mathbf{3 . 4}$ & $\mathbf{6} \pm \mathbf{1 . 8}$ & $\mathbf{6 4} \pm \mathbf{3 . 6}$ & $\mathbf{6 6}$ \\
\hline
\end{tabular}

1Total number of characterized boundaries.

${ }^{2}$ CSLB proportion for $\Sigma \leq 49$.

${ }^{3}$ Proportion of CSLBs that are twin related, that is, $\Sigma 3, \Sigma 9$, and $\Sigma 27$ boundaries.

GBCDs for all the characterized samples are listed in Table 4. The error values represent plus or minus one standard deviation in percent of total boundaries. Following Knoll (1979), if we assume that each GBCD measurement can be obtained from a large binomial distribution of similar measurements from similarly treated specimens (e.g., the GHAB proportion for specimen $A 1$ is assumed to have been taken from a binomial distribution of GHAB measurements from specimens similar to $A 1$ ), then the sample variance $s_{t}$ can be assumed to be equal to the standard deviation for the distribution. That is,

$$
\mathrm{s}_{\mathrm{t}}^{2} \cong \sigma_{\mathrm{t}}^{2}=\mathrm{n}_{\mathrm{t}}\left(1-\mathrm{p}_{\mathrm{t}}\right)
$$

where $s_{t}$ is the sample variance for a measurement of a type of boundary (LAB, CSLB, or GHAB), $\sigma_{t}$ is the standard deviation of a distribution of measurements of boundary type, $n_{t}$ is the number of boundaries of that type, and $p_{t}$ is the proportion of boundaries of the type. The error bound values are thus the standard deviation $\sigma_{t}$ divided by the total number of boundaries $n_{t}$ characterized for the metal specimen.

The results indicate that a sequence of thermomechanical treatment steps can cumulatively reduce an alloy's proportion of GHABs and increase the proportion of CSLBs. Considering the ineffectiveness of repeating the $3 \%$ deformation steps and starting with the $3 \%$ deformation step alone (sample B2), the best results were obtained by starting with moderate amounts of deformation (5-10\% strain) and proceeding through smaller amounts of deformation (2-3\% strain). The GBCD found in sample C2 confirms this. This behavior may be particularly characteristic of the large grain size used in this work.

\section{Recrystallization and Polygonization}

While some treatments resulted in a predominantly recrystallized structure, others resulted in a predominantly recovered (polygonized) structure. This can be discerned on macroscopic samples in two ways: 1) Backscattered electron images of grains on the sample 

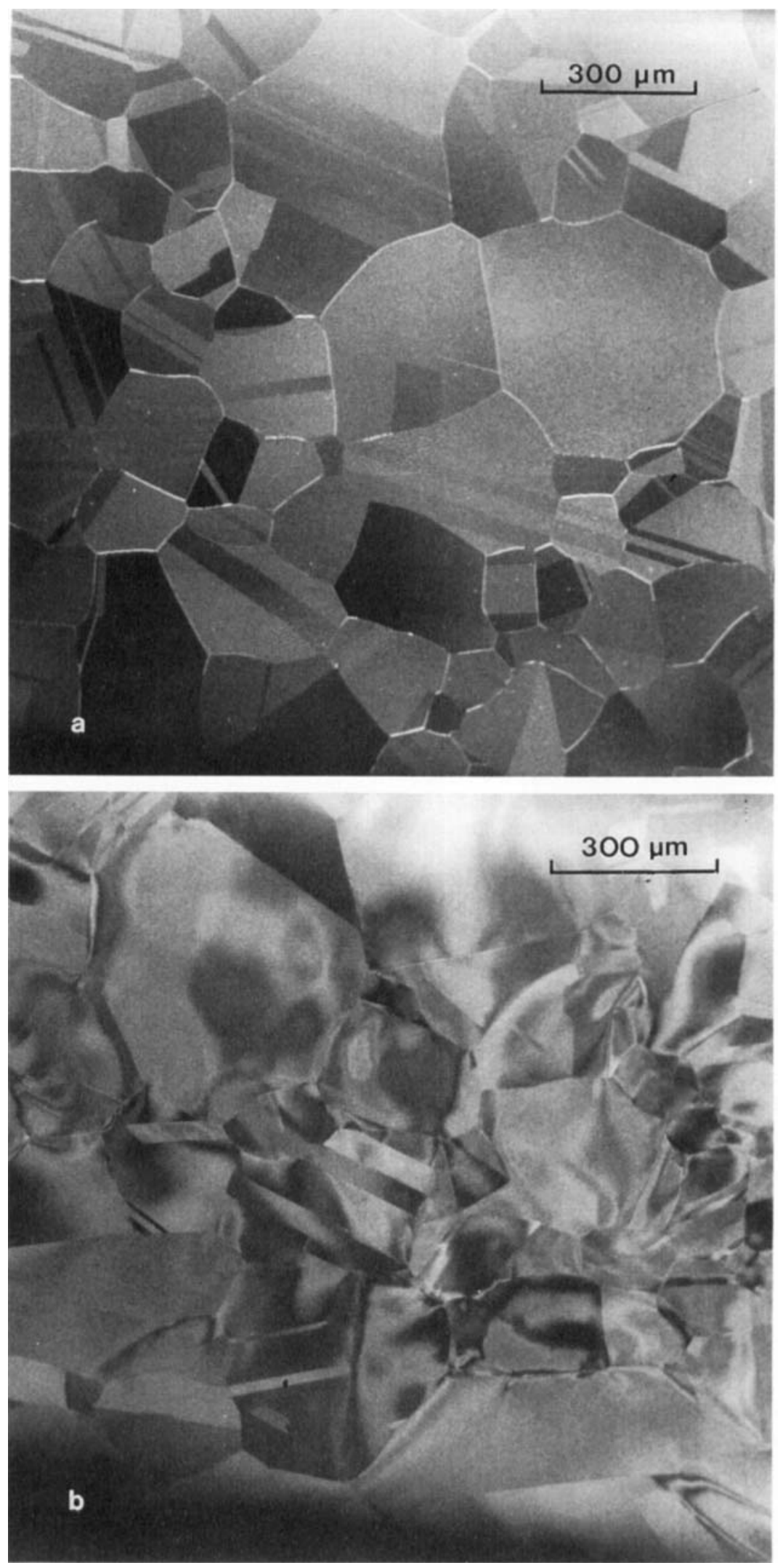

Fig. 7. Backscattered electron images from surfaces of (a) recrystallized sample $\mathrm{Cl}$ and (b) polygonized sample B2. 

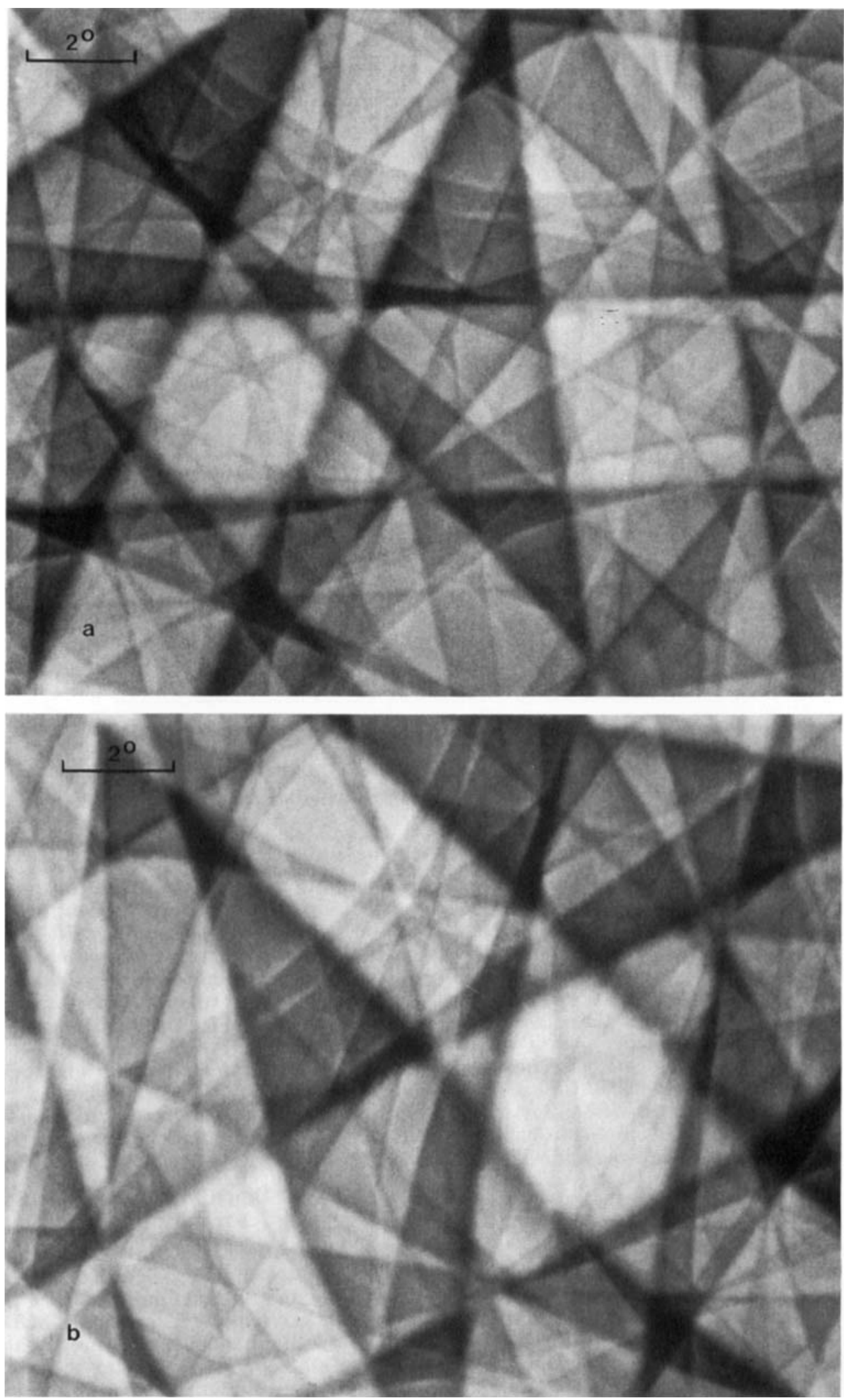

Fig. 8. Selected area channeling patterns from (a) a recrystallized grain and (b) a polygonized grain. 

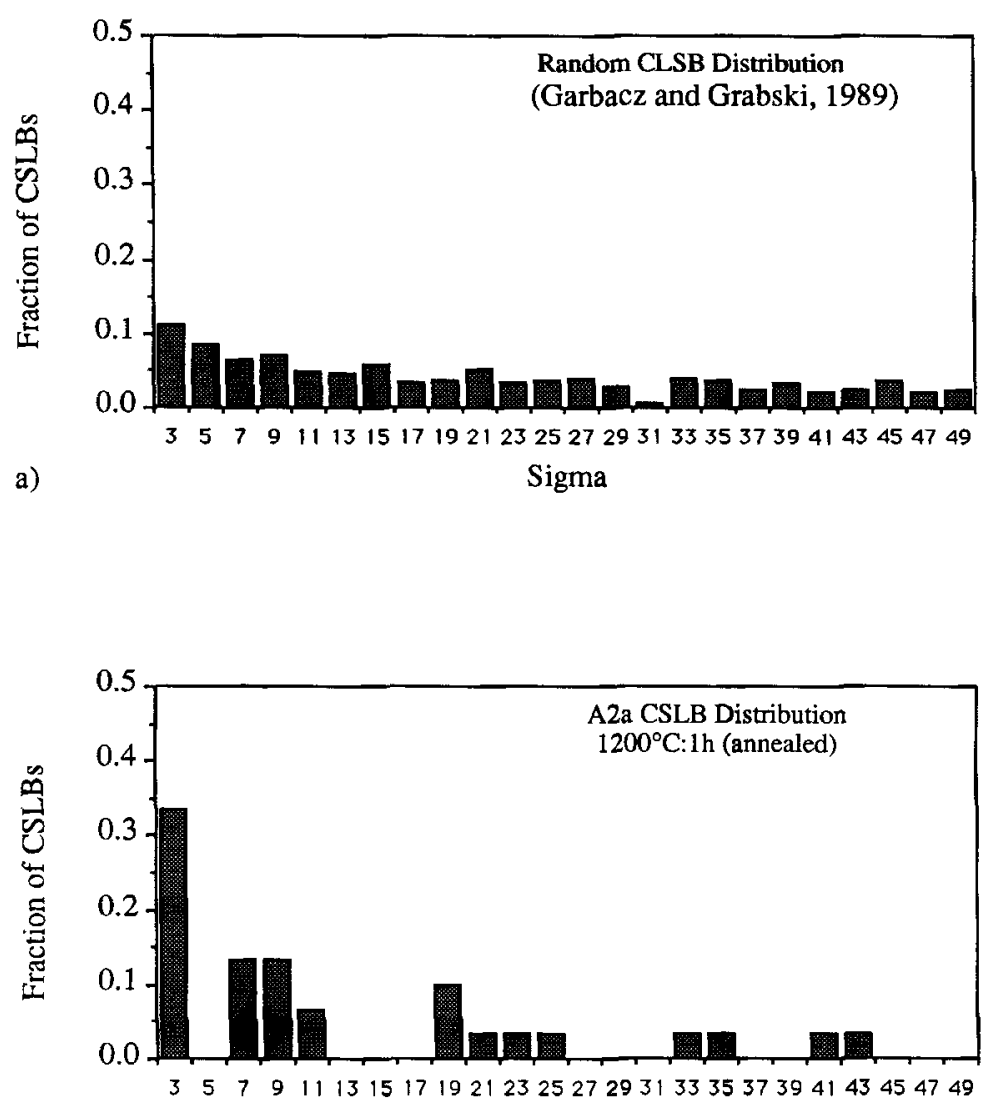

b)

Sigma

Fig. 9. Distribution of Proportions of CSLBs by $\Sigma$ for (a) Garbacz and Grabski's (1989) random distribution and (b) annealed sample A2a.

surface will show uniform channeling contrast across a recrystallized grain (Fig. 7a) and non-uniform channeling contrast across a polygonized grain (Fig. 7b), and 2) SACPs from a recrystallized grain will show sharp contrast and straight channeling bands (Fig. 8a), while SACPs from polygonized grains might also show crisp contrast (though generally less crisp than those from annealed grains), but their channeling bands will be curved and distorted (Fig. 8b). The effects of deformation on channeling contrast and on SACPs are discussed in the literature (Davidson, 1984; Joy et al., 1982; Newbury et al., 1986). Table 3 indicates which of the characterized samples recrystallized and which did not.

The annealed samples are recrystallized, but not all of the thermomechanically treated samples are recrystallized. Interestingly, the only tensile-deformed samples that are recrystallized are those that exhibited the enhanced GBCDs. (Note that sample A2f did not recrystallize, and the GBCD for that step did not change from that of the previous step.) However, the only predominantly polygonized compression-deformed sample was sample Blc, with an enhanced GBCD. This may indicate that the enhanced proportions of CSLBs in the tensile-deformed samples resulted mostly from bound- ary migration and impingement during recrystallization (discussed in the next section), while that of the compression-deformed sample could be due mainly to grain rotation processes. The presence of a polygonized structure after intermediate tensile-deformation steps indicate that grain rotation processes during recovery may be responsible for the small increase in CSL proportions observed after those steps. Perhaps the polygonized structure in a material after recovery from moderate amounts of strain helps produce a strain energy distribution after further deformation that enables the grain rotation or recrystallization processes to activate.

\section{CSLB Distributions and Deviations From Coincidence}

The distributions of CSLBs by $\Sigma$ number resulting from the processing steps is also of interest. Figure $9 \mathrm{a}$ shows the expected distribution of CSLBs from Garbacz and Grabski's simulated random GBCD. In general, the lower $\Sigma$ number boundaries are slightly more prevalent with $\Sigma 3$ boundaries having the highest probability of occurrence. Figure $9 \mathrm{~b}$ shows the CSLB distribution for the annealed sample A2. This distribution appears to be non-random, particularly for $\Sigma 3$ bound- 


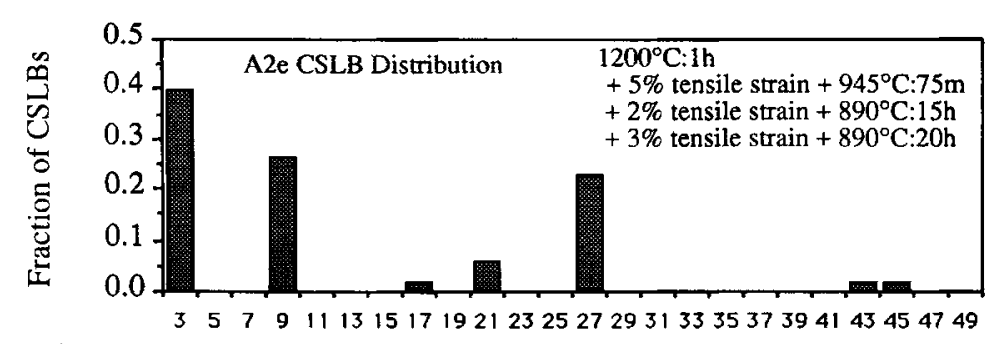

a)

Sigma

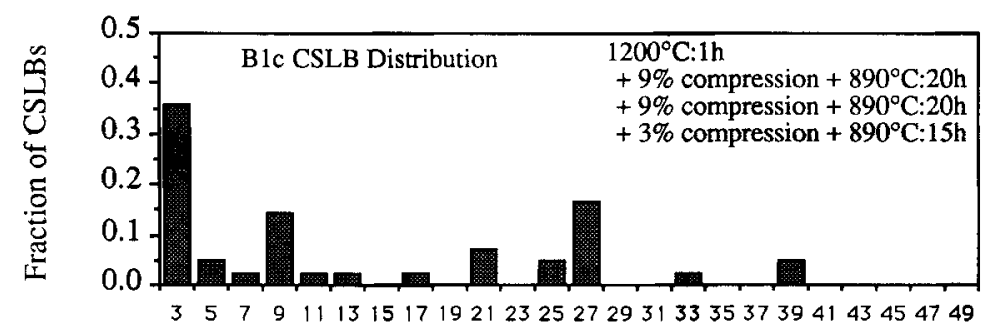

b)

Sigma

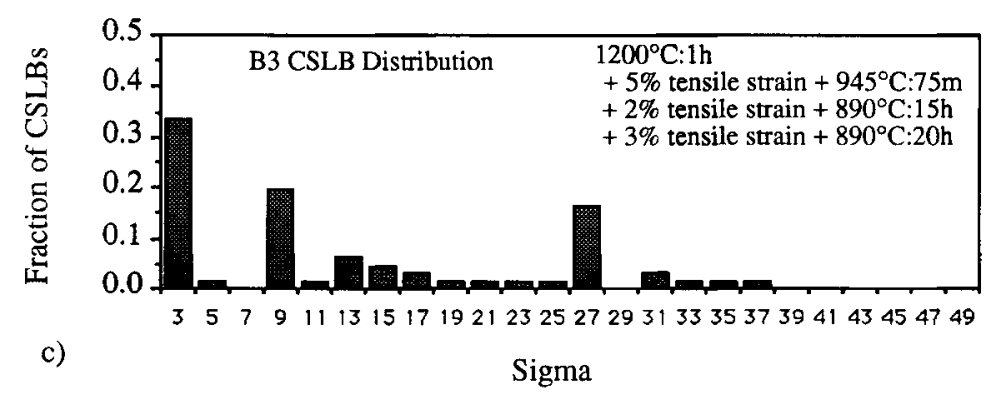
B3.

Fig. 10. Distribution of proportions of CSLBs by $\Sigma$ for (a) sample A2e, (b) sample B1c, and (c) sample

aries. The high proportion of $\Sigma 3$ CSLBs might be expected based on the relatively lower stacking fault energy of nickel-base alloys (Murr, 1975). Lim and Raj (1984) found an increased proportion of $\Sigma 3$ boundaries in strain annealed nickel, but they included coherent twin boundaries in their analysis.

The CSLB distributions (Fig. 10) for the third processing steps of samples A2 and B1 and for sample B3 indicate that these samples have substantially increased proportions of twin-related CSLBs $(\Sigma 3, \Sigma 9, \Sigma 27$ boundaries; hereafter referred to as TRs); note that these samples also have the highest CSLB proportions. During heat treating of deformed samples CSLBs can dissociate into other CSLBs. In fact, it has been shown that $1 / 3$ of CSLBs can dissociate into a $\Sigma 3$ boundary and another low $\Sigma$ boundary; this was used to explain the high proportion of $\Sigma 3$ boundaries in recrystallized aluminum (Watanabe et al., 1981). Such dissociations may also explain the high proportion of $\Sigma 3$ boundaries in the present work. $\Sigma 9$ misorientations can result from the superposition of two $\Sigma 3$ misorientations, $\Sigma 27$ mis- orientations can result from the superposition of a $\Sigma 3$ and a $\Sigma 9$ misorientation, and $\Sigma 3$ misorientations can result from the superposition of $\Sigma 9$ and $\Sigma 27$ misorientations (Randle and Brown, 1989) as well as twinning mechanisms.

Similarly, Randle and Brown (1989) found that the proportion of TRs in the GBCDs of austenitic stainless steel tubing increased with annealing time at $0.72 \mathrm{~T}_{\mathrm{m}}$ after a $2 \%$ tensile strain. Their characterization of this sample after the onset of anomalous growth revealed nearly twice the fraction of TRs as samples characterized before the onset of anomalous growth. They explain this observation by noting that the TR boundaries all have high mobilities (except for coherent twin boundaries) and are likely to encounter other TR boundaries during grain growth (boundary migration)-producing other TR boundaries as noted above. The large TR proportions indicate that boundary impingement during recrystallization is the mechanism responsible for the high CSLB proportions in the recrystallized (tensile-deformed) samples. The poly- 

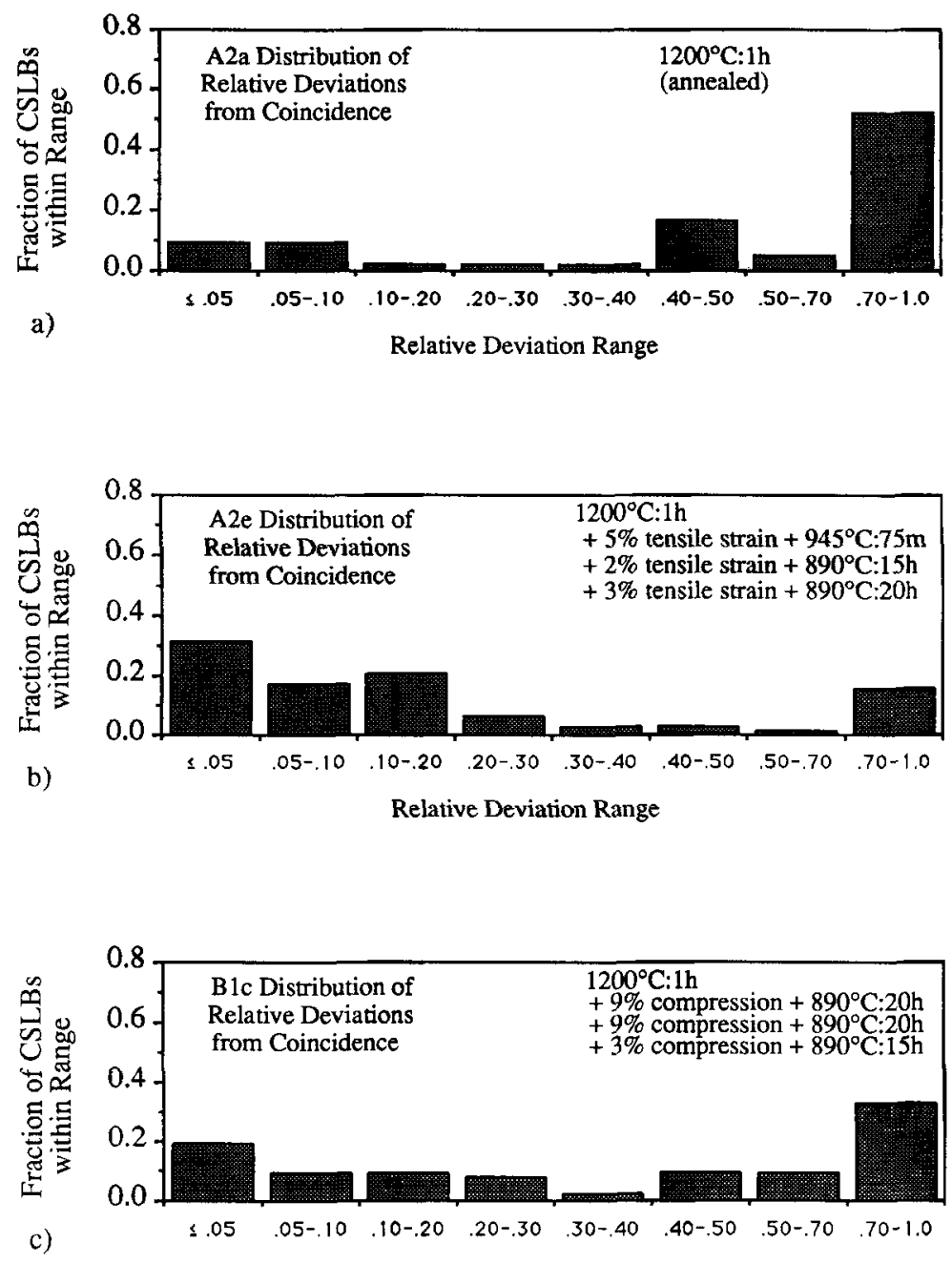

Relative Deviation Range

Fig. 11. Distributions of relative deviations from exact coincidence for CSLBs in samples (a) A2a, (b) A2e, and (c) B1c.

gonized structure and the somewhat lower TR proportion (relative to the recrystallized samples A2e and A3) of the compression-deformed sample B1c suggest that rotation processes may have played a larger role in the observed GBCD for this sample. The TR proportions of the CSLBs found in all the characterized samples are listed in Table 4.

Preferred orientation of grains would also have an effect on the distribution of CSLBs present if the preferred directions were of low index. For example, if surface normals tended to align among $<110>$ directions, then grain misorientations around $<110>$ directions might be more prevalent than those around other low index directions. Thus, one would expect to find more CSLBs with $<110\rangle$ misorientation axes, such as $\Sigma 3, \Sigma 9, \Sigma 11, \Sigma 17, \Sigma 27$, etc., and fewer CSLBs with other low index misorientation axes, such as $\Sigma 5, \Sigma 13$, and $\Sigma 25$ around $<100>$ or $\Sigma 7, \Sigma 13$, and $\Sigma 21$ around $<111>$ (Mykura, 1980). The beam directions (which are very

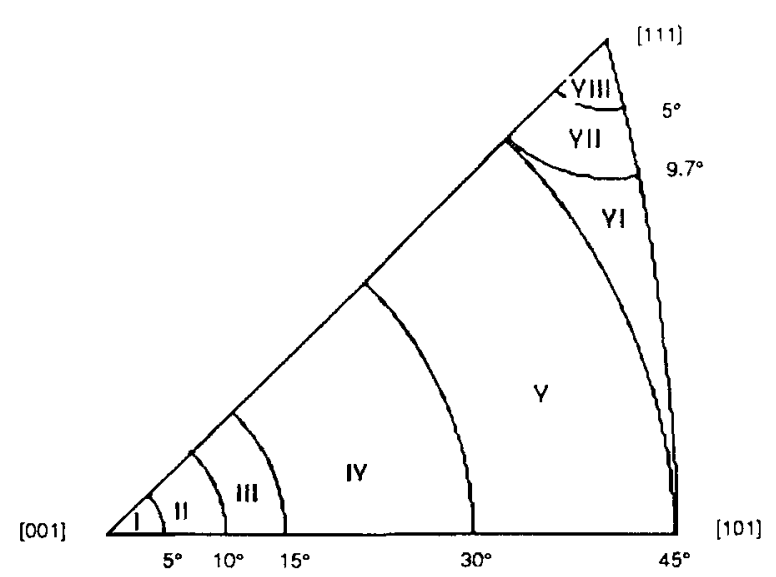

Fig. 12. Stereographic unit triangle showing regions used for Mackenzie's (Mackenzie, 1964) random MOA distribution. 
TABLE 5. Distribution of misorientation axes by stereographic region

\begin{tabular}{|c|c|c|c|c|c|c|c|c|c|}
\hline Sample & I & II & III & IV & V & VI & VII & VIII & $\mathrm{t}$ value \\
\hline Random $^{1}$ & $0.7^{2}$ & 2.1 & 3.6 & 22.7 & 53.4 & 9.4 & 6.0 & 2.1 & - \\
\hline A1 & 0.7 & 2.2 & 0.7 & 17.3 & 56.8 & 10.1 & 7.2 & 5.0 & 3.08 \\
\hline $\mathrm{A} 2 \mathrm{a}$ & 0.7 & 0 & 1.3 & 17.2 & 55.0 & 9.9 & 7.3 & 7.3 & 3.25 \\
\hline $\mathrm{A} 2 \mathrm{~b}$ & 1.6 & 1.6 & 4.9 & 13.1 & 45.9 & 12.3 & 12.3 & 7.4 & 3.58 \\
\hline $\mathrm{A} 2 \mathrm{~d}$ & 1.4 & 0 & 4.1 & 4.1 & 53.4 & 17.8 & 13.7 & 2.7 & 2.11 \\
\hline $\mathrm{A} 2 \mathrm{e}$ & 0 & 0 & 0.9 & 20.9 & 48.7 & 9.6 & 2.6 & 17.4 & 2.26 \\
\hline A2f & 0 & 0 & 3.8 & 18.8 & 43.8 & 2.5 & 2.5 & 27.5 & 2.24 \\
\hline $\mathrm{Bla}$ & 1.0 & 1.0 & 1.9 & 15.5 & 53.4 & 10.7 & 7.8 & 7.8 & 2.58 \\
\hline $\mathrm{BHb}$ & 0 & 0 & 3.4 & 12.1 & 53.4 & 17.2 & 3.4 & 8.6 & 2.71 \\
\hline Blc & 1.8 & 0 & 0.9 & 12.8 & 57.8 & 7.3 & 3.7 & 15.6 & 3.01 \\
\hline B1d & 0 & 0 & 1.1 & 16.3 & 63.0 & 9.8 & 3.3 & 6.5 & 3.28 \\
\hline $\mathrm{B} 2$ & 0 & 0 & 2.2 & 12.4 & 52.8 & 11.2 & 12.4 & 9.0 & 2.95 \\
\hline $\mathrm{B} 3$ & 1.4 & 1.0 & 1.0 & 20.3 & 54.6 & 6.8 & 4.8 & 10.1 & 2.98 \\
\hline $\mathrm{B} 4$ & 0 & 2.6 & 3.9 & 20.4 & 57.9 & 6.6 & 3.3 & 5.3 & 4.09 \\
\hline $\mathrm{C} 1$ & 0.4 & 0.9 & 2.2 & 18.3 & 51.5 & 9.6 & 8.7 & 7.0 & 3.42 \\
\hline $\mathrm{C} 2$ & 0 & 2.8 & 0.6 & 17.4 & 52.8 & 10.7 & 6.2 & 9.0 & 2.63 \\
\hline
\end{tabular}

${ }^{1}$ Taken from Mackenzie (1964).

${ }^{2}$ Values are percentage of total boundaries.

near to the surface normals) for the annealed sample $\mathrm{A} 2 \mathrm{a}$ and the CSLB-enhanced sample A2e were examined to determine how many beam directions were within 5 degrees of low index directions $\langle 100\rangle$, $<110\rangle,<111>,<210>$ and so on up to $<311>$. No more than $9 \%$ of the beam directions were aligned with any one of the crystallographic directions, indicating that neither of these samples has a strong surface texture along low index directions. Because all the twinrelated boundary misorientations have possible misorientation relationships with $\langle 110\rangle$ axes, one might expect to see a stronger $\langle 110\rangle$ surface texture in sample A2e which has the large TR proportions. However, the fractions of beam directions near $\langle 110\rangle$ for both the annealed and CSLB-enhanced samples were nearly the same, approximately $9 \%$ for the annealed sample and $7 \%$ for the CSLB-enhanced sample. Therefore, the high TR proportions in the CSLB-enhanced samples cannot be correlated with surface texture.

Comparison of relative deviations from exact CSL misorientations $\left(\Delta \theta / \Delta \theta_{b}\right)$ for the CSLBs indicates that the samples with enhanced proportions of CSLBs have more CSLBs with misorientations close to exact coincidence (CSL misorientation). Figure 11 shows the relative deviations from exact coincidence for the CSLBs in annealed sample A2a, sample A2e, and sample B1c. This result is contrary to what Randle and Brown (1989) observed in austenitic stainless tubing. They reported that as the proportion of CSLBs increased, the CSLBs tended toward larger deviations from exact coincidence. CSLBs that are farther away from exact coincidence have more open structures, and thus some of these boundaries have relatively high mobilities (Gordon and Vandermeer, 1966; Pumphrey, 1976). The authors suggested that the buildup of high mobility CSLBs was responsible for the secondary recrystallization seen in their samples. The tendency of CSLBs in the present work to have orientations nearer to exact coincidence might indicate that although their GBCDs are CSLB-rich, material in that condition is no longer susceptible to secondary recrystallization. Of course the present grain sizes are relatively large (300$460 \mu \mathrm{m})$ after the thermomechanical treatment steps; and the presence of anomalously large grains in the annealed samples indicates that the samples have experienced secondary recrystallization prior to the start of processing. It is possible that this apparently low remaining driving force for secondary recrystallization in the processed samples is either the result or the cause of the relatively near coincidence of the CSLBs.

\section{Distribution of Misorientation Axes}

Based on geometrical probabilities, Mackenzie (1964) calculated the random distribution of misorientation (MOAs) in regions of the stereographic unit triangle, as indicated in Figure 12. Mackenzie's expected proportions of MOAs in each region for a random distribution are listed in Table 5 with the corresponding proportions of MOAs for the present work. The distribution of MOAs has been used to indicate the presence of a grain misorientation texture (Randle and Brown, 1988; Randle and Ralph, 1988b).

If a GBCD had non-random proportions of boundary types, then it might be expected to show a non-random distribution of MOAs. Comparison of the distributions of MOAs found in the present work to Mackenzie's distribution will indicate their randomness. The numbers of MOAs in each sample that fall within each stereographic region $\left(z_{i}\right)$ can be compared to the number $\left(y_{i}\right)$ expected from a similar sized sampling of misorientations from a random distribution. Error bounds can be placed on the experimental data in a manner similar to that discussed for the GBCDs. Thus, the error placed on each number of boundaries within a stereographic region is given by $\pm \sigma_{1}$ where

$$
\sigma_{1}^{2} \cong \mathbf{z}_{\mathbf{i}}\left(1-\mathbf{z}_{\mathbf{i}} / \mathbf{n}\right)
$$

where $z_{i}$ is the number of boundaries in region $i$, and $n$ is the total number of boundaries characterized. If $f_{i}$ is the proportion of randomly distributed MOAs in region i, then

$$
\mathbf{y}_{\mathbf{i}}=\mathbf{f}_{\mathbf{i}} \mathbf{n}
$$

gives the number of randomly distributed MOAs in 

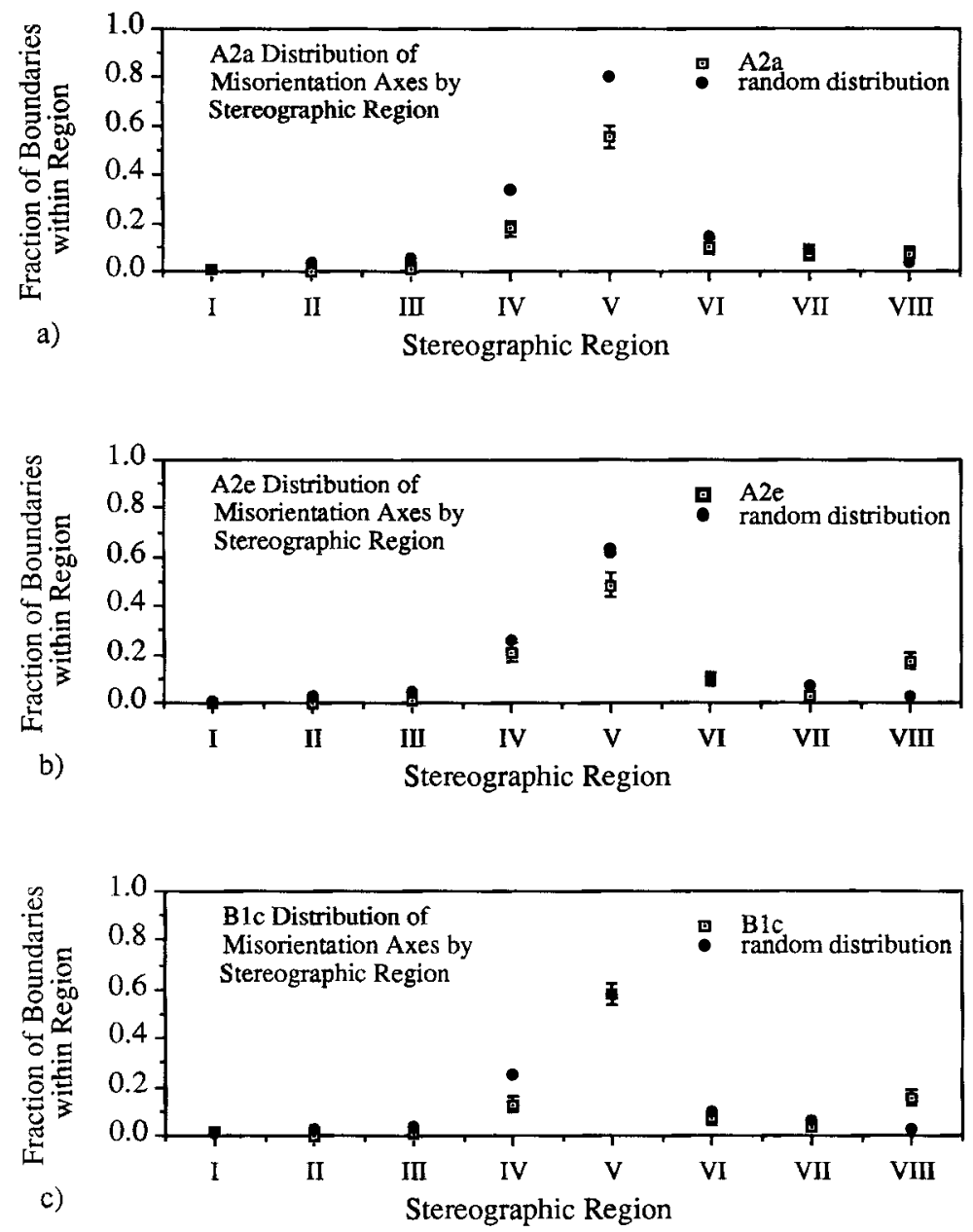

Fig. 13. Distributions of MOAs by the stereographic regions indicated in Figure 12 for samples (a) $\mathrm{A} 2 \mathrm{a}$, (b) A2e, and (c) B1c. For comparison, Mackenzie's (1964) random distribution is plotted for each sample.

region $i$. If for a given sample, the $y_{i}$ values fall within $\pm \sigma_{i}$ of the corresponding $z_{i}$ values, then the experimental distribution can be considered random. Figure 13 compares the MOA distributions for samples A2a, A2e, and B1c with Mackenzie's random distribution.

Some of the random distribution values plotted in Figure 13 do not lie within the error bars for the corresponding experimental values, indicating that the MOA distributions are not random. Comparing the tabulated proportions of experimentally determined MOAs listed in Table 5 with MacKenzie's random distribution shows that the samples with high proportions of CSLBs (A2e, B1c, B3) tend to have relatively more MOAs falling within region VIII (near $<111>$ ). The annealed samples also appear to have a higher than random proportion of MOAs lying in region VIII, although to a lesser extent. None of the MOA distributions found in this work appear to be random, and thus the samples all have some GMT.

Randle and Ralph (1988b) used the Student's t-test to indicate the relative degree of departure of the exper- imental distributions from the random distribution. The statistic upon which the test is drawn is the difference between the proportions of MOAs falling within one of the stereographic regions for the experimental and the random distributions. From Freund (1962),

$$
t=x_{a v} \sqrt{7} / s
$$

$\mathrm{x}_{\mathrm{av}}=$ avg of difference values for all 8 regions,

$$
\mathrm{s}=\sum_{\mathrm{i}=1}^{8}\left(\mathbf{x}_{\mathbf{i}}-\mathbf{x}_{\mathrm{av}}\right)^{2} / 7
$$

$x_{i}=$ difference for region $i$.

Table 5 lists the calculated $t$ values for each sample's distribution of MOAs.

The samples with larger $t$ values would be considered to have the more non-random distribution of MOAs. So one might expect the samples with the more enhanced GBCDs to have less randomly distributed 
MOAs. However, the $t$ values indicate that the annealed samples A1, A2a, B4, and C1 actually have MOA distributions that are less random than the enhanced samples A2e and B3. Sample B1c has a t value that is similar to the annealed samples. Note that as B1 progressed through the sequence of compressive thermomechanical treatment steps, its MOA distribution became more random. Sample A2 did not show any such trend. These results show that for the present work, there is no consistent correlation between a sample's GBCD and its grain misorientation texture.

\section{SUMMARY}

With the use of a computer-aided scheme, GBCDs were determined for ultra high purity $\mathrm{Ni}-16 \mathrm{Cr}-9 \mathrm{Fe}$ samples before and after thermomechanical treatments that were applied in hopes of altering the GBCDs. Based on the statistical analysis described above, characterization of around 150 grain boundaries gives proportions of GHABs and CSLBs with sample variances of approximately $3.5 \%$ of the total number of boundaries. The processing sequences that decreased GHAB proportions the most were those that began with moderate amounts of strain (5-9\%) with a subsequent heat treatment near $0.72 \mathrm{~T}_{\mathrm{m}}$ followed by deformation steps inducing smaller amounts of strain (2$3 \%$, again with a subsequent heat treatment near $0.72 \mathrm{~T}_{\mathrm{m}}$. Successful thermomechanical treatment sequences were able to reduce proportions of GHABs from $76-79 \%$ as seen in the annealed samples to values as low as $50-60 \%$.

Backscattered electron images and SACPs taken from the surfaces of processed samples indicated that some samples had recrystallized while others had polygonized (recovered). The tensile-deformed samples with the lowest proportions of GHABs had experienced total or extensive recrystallization, indicating that the evolved GBCDs resulted mostly from the impingement of migrating CLSBs that left high proportions of TR boundaries. Grain rotation apparently played a greater role in the GBCD evolution of the compressiondeformed sample. However, both boundary impingement and grain rotation are likely involved in the GBCD evolution of all the samples characterized.

Analysis of the distributions of MOAs through the stereographic unit triangle indicates that all the characterized samples contain some GMT. The annealed samples appeared to have MOA distributions that were more non-random than did the processed samples. However, the MOA distributions did not correlate well with GBCD evolution.

\section{ACKNOWLEDGMENTS}

The authors are grateful to David Joy, Tadao Watanabe, and Valerie Randle for their helpful discussion and advice. In addition, the authors are grateful to John Mansfield and personnel at the Electron Microbeam Analysis Laboratory at the University of Michigan for their assistance in developing the capability to do this work. This work is supported by the U.S. Department of Energy under contract DE-FG0285ER45184.

\section{REFERENCES}

Bennett, B.W., and Pickering, H.W. (1987) Effect of grain boundary structure on sensitization and corrosion of stainless steel. Met, Trans. A, 18A:1117-1124.

Brandon, D. (1966) The structure of high angle grain boundaries. Acta Metall., 14:1479-1484.

Butron-Guillen, M., Cabanas-Moren, J., and Weertman, J. (1990) Fatigue cavitation and relative grain misorientations in pure copper. Scripta Metall., 24:991-996.

Chou, Y.T., Cai, B.C., Romig, A.D. Jr., and Lin, L.S. (1983) Correlation between grain-boundary hardening and grain-boundary energy in niobium bicrystals. Phil. Mag. A, 47A:363-368.

Davidson, D. (1984) Uses of Electron channeling in studying material deformation. Int'l. Met. Rev., 29:75-95.

Dingley, D.J., Longden, M., Weinbrein, J., and Alderman, J. (1987) On-line analysis of electron back scatter diffraction patterns. Scanning, 1:451-456.

Don, J., and Majumdar, S. (1986) Creep cavitation and grain boundary structure in type 304 stainless steel. Acta Metall., 34:961-967.

Farrow, R.C., and Joy, D.C. (1981) A new technique for electron channeling pattern measurements. Scanning Electron Microscopy, 1: 397-402,

Freund, J.E. (1962) Mathematical Statistics. Prentice-Hall, Inc., Englewood Cliffs, NJ, pp. 201-203, 259-269.

Garbacz, A., and Grabski, M.W. (1989) Modelling of CSL boundaries distribution in polycrystals. Scripta Metall., 23:1369-1374.

Gordon, P., and Vandermeer, R. (1966) Grain boundary migration. In: Recrystallization, Grain Growth and Textures, ASM, Metals Park, $\mathrm{OH}$, pp. 205-266.

Heilmann, P., Clark, W.A.T., and Rigney, D.A. (1982) Computerized method to determine crystal orientations from Kikuchi patterns. Ultramicroscopy 9:365-372.

Ishida, Y., Mori, M., Arimoto, A., and Once, M. (1981) Computeraided analysis of grain boundary distributions in textured and nontextured specimens from selected area electron channeling patterns. In: Proceedings of the Sixth International Conference on Textures of Materials (ICOTOM-6), Vol. 1, Japanese Iron and Steel Institute, Japan, pp. 601-608.

Joy, D., Newbury, D., and Davidson, D. (1982) Electron channeling patterns in the scanning electron microscope. J. Appl. Phys., 53: R81-R122.

Knoll, G.F. (1979) Radiation detection and measurement. John Wiley and Sons, New York, pp. 118-131.

Kokawa, H., Watanabe, T., and Karashima, S. (1981) Sliding behaviour and dislocation structures in aluminum grain boundaries. Phil. Mag. A, A44:1239.

Lim, C., and Raj, R. (1984) Effect of boundary structure on slip-induced cavitation in polycrystalline nickel. Acta Metall., 32:11831190.

Mackenzie, J.K. (1964) The distribution of rotation axes in a random aggregate of cubic crystals. Acta Metall., 12:223-225.

Murr, L.F. (1975) Interfacial Phenomena in Metals and Alloys. Addison Wesley Publishing Company, Reading, MA, pp. 145-148.

Mykura, H. (1980) A checklist of cubic coincidence site lattice relations. In: Grain Boundary Structure and Kinetics, ASM, Metals Park, OH, pp. 445-456.

Newbury, D., and Joy, D. (1971) A computer technique for the analysis of electron channeling patterns. In: Proceedings of the 25th Anniversary Meeting of EMAG, Inst. Physics, London, pp. 306309.

Newbury, D., Joy, D., Echlin, P., Fiori, C., and Goldstein, J. (1986) Advanced Scanning Electron Microscopy and X-Ray Microanalysis. Plenum Press, New York and London, pp. 123-136.

Ogura, T., Watanabe, T., Karashima, S., and Matsumoto, T. (1987) Dependence of phosphorous segregation on grain boundary crystallography in an Fe-Ni-Cr alloy. Acta Metall., 35:1807-1814.

Ortner, S.R., and Randle, V. (1989) A study of the relationship between grain boundary type and sensitisation in a partially-sensitised AISI 304 stainless steel using electron back-scattering patterns. Scripta Metall., 23:1903-1908.

Priester, L. (1989) Geometrical specialty and special properties of grain boundaries. Revue Phys. Appl., 24:419-438.

Pumphrey, P.H. (1976) Special high angle grain boundaries. In: Grain Boundary Structure and Properties. D.A. Chadwick and G.A. Smith, eds. Academic Press, London, pp. 139-200.

Randle, V., and Brown, A. (1988) The effects of strain on grain misorientation texture during the grain growth incubation period. Phil. Mag. A, 58:717-736. 
Randle, V., and Brown, A. (1989) Development of grain misorientation texture, in terms of coincident site lattice structures, as a function of thermomechanical treatments. Phil. Mag. A, 59:10751089.

Randle, V, and Ralph, B. (1987) Influence of strong grain-boundary pinning by particles upon grain-boundary structure during postrecrystallization anneals. J. of Mat. Sci., 22:2535-2541.

Randle, V., and Ralph, B. (1988a) Grain-specific texture measurements. Textures and Microstructures, 8 \& 9:531-549.

Randle, V., and Ralph, B. (1988b) Local texture changes associated with grain growth. Proc. R. Soc. Lond. A, 415:239-256.

Sato, A., Kon, K., Tsujikawa, S., and Hisamatsu, Y. (1986) The effects of grain boundary misorientation and inclination on hydrogen induced cracking of coarse columar crystals. In: Grain Boundary Structure and Related Phenomena: Proceedings of JIMIS-4 (1986), Supplement to Trans. of the Japan Institute of Metals, pp. 773780.

Schvindlerman, L.S., and Straumal, B.B. (1985) Regions of existence of special and non-special grain boundaries. Acta Metall., 33:17351749.

Vale, S. (1985) Computer aided analysis of electron channeling patterns. In: Inst. Phys. Ser. No. 78: Chapter 3, paper presented at EMAG' 85 , Newcastle upon Tyne, pp. 79-82.

Warrington, D.H., and Boon, M. (1975) Ordered structures in random grain boundaries. Some geometrical probabilities. Acta Metall., 23: 599-607.

Was, G.S. (1989) Grain boundary chemistry and intergranular fracture in austenitic nickel-base alloys. Materials Science Forum, 46 : 335-358.

Watanabe, T. (1983) Grain boundary sliding and stress concentration during creep. Met. Trans. A, 14A:531-545.
Watanabe, T. (1984) An approach to grain boundary design for strong and ductile polycrystals. Res. Mechanica, 11:47-82.

Watanabe, T. (1985) Structural effects on grain boundary segregation, hardening, and fracture. Journal de Physique, Colloque C4, supplement au 4, 46:c4-555-c4-566.

Watanabe, T. (1986) Grain boundary design for new materials. In: Grain Boundary Structure and Related Phenomena: Proceedings of JIMIS-4 (1986), Supplement to Trans. of the Japan Institute of Metals, pp. $73-82$.

Watanabe, T., Fuji, H., Oikawa, H., and Arai, K.I. (1989) Grain boundaries in rapidly solidified and annealed Fe-6.5 mass\% Si polycrystalline ribbons with high ductility. Acta Metall., 37:941-952.

Watanabe, T., Kawamata, Y., and Karashima, S. (1986) Grain boundary character distributions for recrystallization structures in $\mathrm{Fe}-3 \%$ Si. In: Grain Boundary Structure and Related Phenomena: Proceedings of JIMIS-4 (1986), Supplement to Trans. of the Japan Institute of Metals, pp. 601-607.

Watanabe, T., Tanaka, M., and Karashima, S. (1982) Intergranular fracture caused by liquid gallium in polycrystalline beta brass with bec structure. In: Proceedings of Embrittlement by Liquid and Solid Metals. M.H. Kamdar, ed. TMS-AIME, Watervliet, NY, pp. 183196.

Watanabe, T., Yamada, M., Shima, S., and Karashima, S. (1979) Misorientation dependence of grain boundary sliding in <10T0> tilt zinc bicrystals. Phil. Mag. A, 40:667-683.

Watanabe, T., Yoshikawa, N., and Karashima, S. (1981) Grain boundary character distributions in recrystallization structures of deformed aluminum single crystals. In: Proceedings of the Sixth In ternational Conference on Textures of Materials (ICOTOM-6), Vol. 1, Japanese Iron and Steel Institute, Japan, pp. 609-618.

Young, C.T., Steele, J.H., and Lytton, J.L. (1973) Characterization of bicrystals using Kikuchi patterns. Met. Trans., 4:2081-2089. 